\title{
PREVALENSI OBESITAS PADA REMAJA DI KABUPATEN MINAHASA
}

\author{
${ }^{1}$ Karina Kussoy \\ ${ }^{2}$ Fatimawali \\ ${ }^{3}$ Billy Kepel
}

\author{
Kandidat skripsi Fakultas Kedokteran Universitas Sam Ratulangi Manado \\ Bagian Kimia Fakultas Kedokteran Universitas Sam Ratulangi Manado \\ Email: karina.kussoy@yahoo.com
}

\begin{abstract}
Obesity is one of today's most blantantly visible yet most neglected public health problems. Obesity has become a global epidemic and one of public health problems that should be handled. Adolescent lifestyle who always skip breakfast and more likely to consume fast food and tend to be sedentary lifestyle, make adolescent at risk for obesity. This study aims to obtain the prevalence of obesity among adolescent in Minahasa. This is a cross-sectional study. Data retrieval is done by measuring the waist circumference of 395 high school student consisting 140 boys and 255 girls. The result show that the prevalence of obesity among adolescent in Minahasa is 26,33\% consisting 4,30\% boys and 22,03\% girls. The prevalens of obesity is high so that education to adolescents, parents, and school about obesity causes, complications, and preventions is needed.
\end{abstract}

Keywords: Obesity.

\begin{abstract}
Abstrak: Di antara berbagai masalah kesehatan di masyarakat, obesitas merupakan salah satu masalah yang terang-terangan terlihat namun paling diabaikan. obesitas telah menjadi suatu epidemik global dan merupakan masalah kesehatan yang harus segera di tangani. Gaya hidup remaja saat ini yang sering melewatkan sarapan dan lebih suka mengkonsumsi fast food. serta cenderung sedentary life style, membuat remaja berisiko untuk menderita obesitas. Penelitian ini bertujuan untuk mengetahui prevalensi obesitas pada remaja di kabupaten Minahasa. Penelitian ini menggunakan desain potong lintang. Pengambilan data dilakukan dengan pengukuran lingkar pinggang pada 395 orang siswa SMK yang terdiri dari 140 orang siswa lakilaki dan 255 orang siswa perempuan. Hasil penelitian menunjukan prevalensi obesitas pada remaja di Minahasa adalah 26,33\% yang terdiri dari 4,30\% remaja laki-laki dan 22.03\% remaja perempuan. Angka prevalensi obesitas yang didapatkan cukup tinggi sehingga perlu dilakukan edukasi kepada siswa, orang tua dan sekolah mengenai penyebab, bahaya dan pencegahan obesitas.
\end{abstract}

Kata Kunci: Obesitas.

Dewasa ini di antara berbagai masalah kesehatan di masyarakat, obesitas merupakan salah satu masalah yang terangterangan terlihat namun paling diabaikan. ${ }^{1}$ Obesitas saat ini merupakan permasalahan yang muncul diseluruh dunia, bahkan WHO menyatakan obesitas sebagai suatu epidemik global dan merupakan masalah kesehatan yang harus segera di tangani. ${ }^{2}$

Obesitas dapat diartikan sebagai penimbunan jaringan lemak tubuh secara berlebihan yang memberi efek buruk pada kesehatan. Kondisi ini dapat di alami oleh setiap golongan umur baik laki-laki maupun perempuan, akan tetapi remaja dan dewasa merupakan kelompok yang paling sering terjadi. Gaya hidup remaja saat ini yang sering melewatkan sarapan dan lebih suka mengkonsumsi fast food. serta cenderung sedentary life style, membuat remaja berisiko untuk menderita obesitas. ${ }^{3}$ Prevalensi kelebihan berat badan 
(overweight) dan obesitas pada saat ini telah terbukti meningkat sangat tajam di seluruh dunia dan telah mencapai tingkatan yg membahayakan. Menurut laporan WHO tahun 2003, 300 juta orang dewasa menderita obesitas. Di Amerika Serikat, 1 dari 3 orang penduduk menderita obesitas, di Inggris 16$17,3 \%$ penduduk menderita obesitas.

Prevalensi overweight (kegemukan) dan obesitas meningkat sangat tajam di kawasan Asia-Pasific, contohnya 20,5\% dari penduduk Korea Selatan tergolong overweigth dan $1,5 \%$ tergolong obes. Di Thailand, $16 \%$ penduduknya mengalami overweight dan $4 \%$ mengalami obesitas .

Hasil Riset Kesehatan Dasar Nasional (Riskesdasnas) tahun 2010, prevalensi kegemukan pada anak umur 13-15 tahun adalah 2,5\%. Ada 15 provinsi yang memiliki prevalensi kegemukan pada anak 13-15 tahun di atas prevalensi nasional, yaitu Provinsi Sumatera Utara, Sumatera Barat, Jambi, Bengkulu, Kepulauan Bangka Belitung, DKI Jakarta, Jawa Tengah, DI Yogyakarta, Banten, Bali, Kalimantan Selatan, Kalimantan Timur, Sulawesi Utara, Sulawesi Tenggara dan Papua. Untuk prevalensi kegemukan pada anak 16-18 tahun adalah $1,4 \%$. Terdapat 11 provinsi yang memiliki prevalensi kegemukan pada anak 16-18 tahun diatas prevalensi nasional, yaitu Provinsi Kepulauan Bangka Belitung, Kepulauan Riau, DKI Jakarta, Jawa Barat, DI Yogyakarta, Jawa Timur, Kalimantan Selatan, Sulawesi Utara, Gorontalo, Papua Barat dan Papua. ${ }^{5}$

Etnis Minahasa di Provinsi Sulawesi Utara mempunyai kebiasaan makan yang cukup unik dengan beragam makanan yang khas yang sebagian besar mengandung asam lemak jenuh tinggi, masyarakat etnis Minahasa juga yang sebagian besar beragama Kristen mempunyai suatu kebiasaan party yang diikuti dengan pesta makan makanan khas Minahasa yang sebagian besar berasal dari lemak hewani (babi). ${ }^{6}$ Prevalensi obesitas pada remaja di kota Manado tahun 2005 adalah 9,88\%, ${ }^{7}$ sedangkan Prevalensi remaja obesitas di kota tomohon pada tahun 2010 sebesar 35\%. ${ }^{8}$
Berdasarkan latar belakang ini maka penulis merasa perlu dan tertarik untuk melakukan penelitian tentang prevalensi obesitas pada remaja di Minahasa.

\section{METODE PENELITIAN}

Penelitian ini bersifat cross-sectional dengan pendekatan deskriptif. Penelitian ini dilakukan di SMK negeri di kota Tondano. Penelitian ini dalam pelaksanaannya dari persiapan, pengumpulan data, analisis data, hingga diseminarkan dilaksakan dari bulan Agustus 2012 - Januari 2013. Populasi adalah remaja yang berusia 13-18 tahun di kabupaten Minahasa. Sampel adalah siswa SMK di kota Tondano. Pengambilan sampel menggunakan cara Simple Random Sampling. Kriteria Inklusi yaitu siswa yang berusia 13 tahun - 18 tahun, sehat, terdaftar, dan aktif mengikuti kegiatan sekolah dan siswa yang bersedia menandatangani surat persetujuan untuk dijadikan sampel penelitian. Kriteria eksklusi adalah siswa yang menderita penyakit kronis. Definisi operasional obesitas dinilai dengan mengukur lingkar pinggang. Tempat pengukuran diantara tulang panggul bagian atas dan tulang rusuk bagian bawah. Pengkategorian obesitas berdasarkan nilai ukuran lingkar pinggang, untuk laki-laki $>90 \mathrm{~cm}$, dan untuk wanita $>80 \mathrm{~cm}$ (International Diabetes Federation, 2005). Remaja adalah anak-anak yang berusia antara 13-18 tahun (Hurlock, 1981). Instrumen penelitian yang digunakan yaitu pita pengukur lingkar pinggang dan alat tulis menulis. Pengumpulan data dilakukan dengan pengukuran lingkar pinggang, pengukuran lingkar pinggang dilakukan dalam posisi berdiri tegak dan tenang. Baju penghalang pengukuran disingkirkan. Letakkan pita pengukur di tepi atas crista illiaca. Yakinkan bahwa pita pengukur tidak menekan kulit terlalu ketat dan sejajar dengan lantai. Pengukuran dilakukan saat akhir ekspirasi normal. Nyatakan lingkar pinggang dalam $\mathrm{cm}$. Data yang diperoleh kemudian di kumpul, diolah, ditabulasi, dan diambil rata-rata. 


\section{HASIL PENELITIAN}

Penelitian dilakukan sejak bulan Agustus 2012 sampai bulan Januari 2013 dan untuk pengambilan data dilakukan sejak bulan November 2012 sampai bulan Januari 2013 di SMK Negeri di Kota Tondano, penelitian ini diawali dengan membuat surat persetujuan penelitian dengan Dinas Pendidikan, Pemuda, dan Olah Raga Kabupaten Minahasa, setelah itu surat tersebut diserahkan kepada kepala sekolah di SMK yang akan menjadi lokasi penelitian.

Subjek dalam penelitian ini adalah remaja yang berusia 13-18 tahun yang merupakan siswa SMK kelas 10 sampai kelas 12.

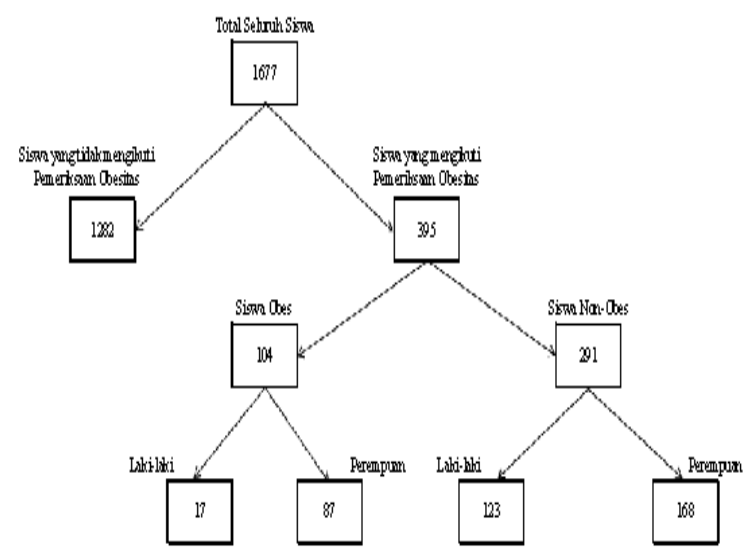

Gambar 1. Skema pengambilan data

Jumlah populasi adalah 1167 dan diambil 395 orang sebagai subjek secara simple random sampling untuk dilakukan pengukuran lingkar pinggang. Dari hasil pengukuran yang dilakukan diperoleh 104 orang siswa yang memiliki lingkar pinggang $>80$ bagi perempuan dan $>90$ bagi laki-laki.

Tabel 1. Prevalensi obesitas pada remaja di Kabupaten Minahasa

\begin{tabular}{llcccc}
\hline No & $\begin{array}{c}\text { Jenis } \\
\text { Kelamin }\end{array}$ & $\mathrm{N}$ & \multicolumn{3}{c}{ Lingkar Pinggang } \\
\cline { 3 - 6 } & & $\begin{array}{c}\text { Normal } \\
(\%)\end{array}$ & $\begin{array}{c}\text { Obesitas } \\
(\%)\end{array}$ & $\%$ \\
\hline 1 & Laki-laki & 140 & $\begin{array}{c}123 \\
(31,14)\end{array}$ & $17(4,30 \%)$ & 100 \\
\hline 2 & Perempuan & 255 & $\begin{array}{c}168 \\
(42,53)\end{array}$ & $87(22,03)$ & 100 \\
\hline & Total & 395 & $\begin{array}{c}291 \\
(73,67 \%)\end{array}$ & $\begin{array}{c}104 \\
(26,33 \%)\end{array}$ & 100 \\
\hline
\end{tabular}

Pada Tabel 1 diatas menunjukan dari 395 orang remaja yang diukur lingkar pinggangnya ditemukan 104 orang remaja yang mengalami obesitas, terdiri dari 17 orang remaja laki-laki (4,30 \%) dan 87 orang remaja perempuan (22,03\%), sedangkan untuk 291 (73,67\%) siswa yang lain yang diukur lingkar pinggangnya tidak mengalami obesitas atau memiliki berat badan yang normal.

Tabel 2. Nilai minimum, nilai maksimum, ratarata, dan standart deviasi pada pengukuran lingkar pinggang

\begin{tabular}{cccccc}
\hline & $\mathrm{N}$ & Min & Maks & Mean & SD \\
\hline $\mathrm{L}$ & 140 & $60 \mathrm{~cm}$ & $116 \mathrm{~cm}$ & 75,02 & $\pm 9,91$ \\
\hline $\mathrm{P}$ & 255 & $55 \mathrm{~cm}$ & $113 \mathrm{~cm}$ & 76,19 & $\pm 8,17$ \\
\hline Total & 395 & & & & \\
\hline
\end{tabular}

Tabel 2 menunjukan dari 395 orang yang diukur lingkar pinggangnya didapatkan nilai minimum lingkar pinggang pada lakilaki $60 \mathrm{~cm}$ dan pada perempuan $55 \mathrm{~cm}$. untuk nilai maksimum lingkar pinggang didapatkan $116 \mathrm{~cm}$ pada laki-laki dan 113 $\mathrm{cm}$ pada perempuan. Untuk nilai rata-rata pada laki-laki 75,02 dan pada perempuan 76,19 . Dan untuk standart deviasi pada lakilaki $\pm 9,91$ dan pada perempuan $\pm 8,17$.

Tabel 3. Nilai minimum, nilai maksimum, ratarata, dan standart deviasi lingkar pinggang pada remaja yang obes

\begin{tabular}{cccccc}
\hline & $\mathrm{N}$ & Min & Maks & Mean & SD \\
\hline $\mathrm{L}$ & 17 & $91 \mathrm{~cm}$ & $116 \mathrm{~cm}$ & 94,72 & $\pm 6,13$ \\
\hline $\mathrm{P}$ & 87 & $81 \mathrm{~cm}$ & $113 \mathrm{~cm}$ & 85,57 & $\pm 5,56$ \\
\hline Total & 104 & & & & \\
\hline
\end{tabular}

Tabel 3 menunjukan dari 104 orang remaja yang obes diperoleh nilai minimum lingkar pinggang pada laki-laki $91 \mathrm{~cm}$, pada perempuan $81 \mathrm{~cm}$. untuk nilai maksimum diperoleh $116 \mathrm{~cm}$ pada laki-laki, $113 \mathrm{~cm}$ pada perempuan. Untuk nilai rata-rata diperoleh pada laki-laki 94,72, pada perempuan 85,57. Dan untuk standart deviasi pada laki-laki $\pm 6,13$ dan pada perempuan 5,56 . 


\section{BAHASAN}

Penelitian ini dilaksanakan di SMK Negeri di kota Tondano pada bulan Agustus 2012 sampai bulan Januari 2013 dan pengambilan data pada bulan November 2012 sampai bulan Januari 2013. Pengkategorian obesitas berdasarkan nilai ukuran lingkar pinggang, untuk laki-laki $>90 \mathrm{~cm}$, dan untuk wanita $>80 \mathrm{~cm}$ (International Diabetes Federation, 2005). Sebanyak 395 orang siswa yang berusia 1318 tahun dilakukan pengukuran lingkar pinggang dan ditemukan 104 orang siswa yang mengalami obesitas dengan presentase $26,33 \%$ yang terdiri dari 17 orang siswa laki-laki dengan presentase $4.30 \%$ dan 87 orang siswa perempuan dengan presentase 22,03\%. Hasil ini lebih rendah bila dibandingkan dengan penelitian pada tahun 2010 di kota Tomohon, prevalensi obesitas sebesar 35\% yang terdiri dari 31\% pada remaja perempuan dan $4 \%$ pada remaja lakilaki. $^{8}$ Penelitian pada tahun 2012 di kota Bitung menunjukan prevalensi obesitas sebesar $24 \%$ yang terdiri dari $21 \%$ pada remaja perempuan dan $4 \%$ remaja pada lakilaki. $^{9}$

Hasil Riset Kesehatan Dasar Nasional (Riskesdasnas) tahun 2010, prevalensi obesitas pada anak umur 13-15 tahun adalah 2,5\%. Ada 15 provinsi yang memiliki prevalensi obesitas pada anak 13-15 tahun di atas prevalensi nasional, yaitu Provinsi Sumatera Utara, Sumatera Barat, Jambi, Bengkulu, Kepulauan Bangka Belitung, DKI Jakarta, Jawa Tengah, DI Yogyakarta, Banten, Bali, Kalimantan Selatan, Kalimantan Timur, Sulawesi Utara, Sulawesi Tenggara dan Papua. Untuk prevalensi obesitas pada anak 16-18 tahun adalah 1,4\%. Terdapat 11 provinsi yang memiliki prevalensi obesitas pada remaja usia 16-18 tahun diatas prevalensi nasional, yaitu Provinsi Kepulauan Bangka Belitung, Kepulauan Riau, DKI Jakarta, Jawa Barat, DI Yogyakarta, Jawa Timur, Kalimantan Selatan, Sulawesi Utara, Gorontalo, Papua Barat dan Papua. ${ }^{5}$ Data prevalensi obesitas dalam penelitian ini lebih besar dari data Riskesdas tahun 2010.
Tingginya prevalensi obesitas pada remaja di kabupaten Minahasa ini kemungkinan berhubungan dengan kebiasaan makan remaja yang kurang baik. Aktivitas remaja umumnya banyak di lakukan di luar rumah sehingga sering dipengaruhi oleh teman sebaya, termasuk dalam hal pemilihan makanan. Pemilihan makan sudah bukan lagi berdasarkan kandungan gizi tetapi sekedar bersosialisasi, untuk kesenangan dan agar tidak kehilangan status. ${ }^{10}$ Pada saat sekarang ini umumnya remaja memilih makanan yang tidak membutuhkan waktu lama untuk diolah. Jenis makanan seperti ini dikenal dengan istilah "fast food". Fast food banyak di jumpai di kafe, restoran, maupun kantin sekolah dan identik dengan porsi yang besar dan kandungan natrium yang tinggi. Kebiasaan makan remaja ini lah yang berkontribusi terhadap kejadian obesitas. ${ }^{11}$

Karakteristik etnis Minahasa juga mempengaruhi tingginya prevalensi obesitas pada remaja di kabupaten Minahasa, etnis Minahasa di Provinsi Sulawesi Utara mempunyai kebiasaan makan yang cukup unik dengan beragam makanan yang khas yang sebagian besar mengandung asam lemak jenuh tinggi, masyarakat etnis Minahasa juga yang sebagian besar beragama Kristen mempunyai suatu kebiasaan party yang diikuti dengan pesta makan makanan khas Minahasa yang sebagian besar berasal dari lemak hewani (babi), makanan yang di konsumsi oleh etnis Minahasa sehari-harinya juga cenderung mengandung asam lemak jenuh tinggi. ${ }^{6}$

\section{SIMPULAN}

Prevalensi obesitas pada remaja di kabupaten Minahasa adalah sebesar 26,33\% yang terdiri dari 4,30\% remaja perempuan dan 22,03\% remaja laki-laki.

\section{DAFTAR PUSTAKA}

1. World Health Organisation. Controlling the global obesity epidemic. 2012. Available at: http://who.int/nutrition/topics/obesity/en/ 
2. Obesity: Preventing and Managing The Global Epidemic. WHO Technical Report, Series 2000: 894, Geneva

3. UB, Handoyo, Rohadi P. Hubungan obesitas dengan risiko obstructive sleep apnea (osa) pada remaja. Jurnal Ilmiah Kesehatan Keperawatan. 2012;8:45.

4. Hadi, Hamam. Beban ganda masalah gizi dan implikasinya terhadap kebijakan pembangunan kesehatan nasional. 2005. Available at:

http://gizi.depkes.go.id/wpcontent/upload/20 12/05/Beban-ganda-masalah-gizi.pdf (di akses 19 Oktober 2012)

5. Riset kesehatan dasar nasional. 2010. Available at: www.litbang.depkes.go.id (diakses 2 November 2012)

6. Kandou DG. Kebiasaan makan makanan etnik Minahasa di Provinsi Sulawesi Utara.Jurnal Kesehatan Masyarakat. 2009;3(2):53-7.
7. Tambuwun AI. Prevalensi obesitas dan pola makan pada remaja sltp dengan obesitas di kota manado [skripsi]. Fakultas Kedokteran Universitas Sam Ratulangi; 2005

8. Kussoy DWK. Prevalensi hiperurisemia pada remaja obes di kota Tomohon [skripsi]. Fakultas Kedokteran Universitas Sam Ratulangi Manado; 2009.

9. Monangin P. Prevalemsi hiperurisemia pada remaja obes di SMK Negeri 1Bitung [skripsi]. Fakultas Kedokteran Univrsitas Sam Ratulangi Manado; 2012

10.Heryanti E. Kebiasaan makan remaja [skripsi]. Fakultas Kesehatan Masyarakat Universitas Indonesia; 2009.

11.Odgen CL, Flegal MK. Changes in terminology for childhood overweight and obesity; 25. CDC; 2010. Available at: http://www.cdc.gov/nchs/data/nhsr025.pdf 